\title{
External Auditory Canal Cholesteatoma: Clinical and Radiological Features
}

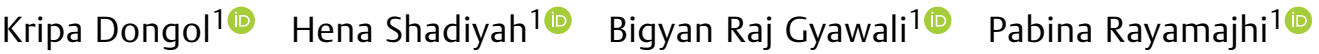 \\ Rabindra Bhakta Pradhananga1ْ \\ ${ }^{1}$ Department of Otorhinolaryngology, Institute of Medicine, \\ Tribhuvan University Kathmandu, Nepal \\ Address for correspondence Kripa Dongol, MBBS, MS, Department of \\ Otorhinolaryngology, Institute of Medicine, Tribhuvan University \\ Maharajgunj, Kathmandu, Nepal, P.O. BOX 1524 \\ Int Arch Otorhinolaryngol 2022;26(2):e213-e218. \\ (e-mail: kripadongol@yahoo.com).
}

\begin{abstract}
Introduction External auditory canal cholesteatoma (EACC) is often misdiagnosed. Objectives To outline the clinical presentation of EACC, and to describe its radiological findings on high-resolution computed tomography (HRCT) of the temporal bone. Methods The clinical records of all patients diagnosed with EACC from April 2017 to March 2020 in a tertiary care center were retrospectively reviewed. The clinical presentation, the findings on the HRCT of the temporal bone, and the treatment provided were analyzed.

Results A total of 9 patients, 7 males and 2 females, with a mean age of 30 years, were diagnosed with primary EACC. Six patients presented with otorrhoea, three, with otalgia, three. with hearing loss, and one with facial palsy. Some patients had multiple symptoms. The most common findings on otomicroscopy were destruction of the posterior and inferior canal walls, with cholesteatoma and intact tympanic membrane (six patients). Two patients had aural polyp, and one had a narrow ear canal due to sagging of the posterior canal wall. On HRCT, all nine patients showed soft-tissue density in the external auditory canal with erosion of the canal wall. The disease

Keywords

- cholesteatoma

- external auditory canal

- radiological

- canal cholesteatoma extended to the mastoid in eight cases, and to the cavity of the middle ear in one. There were three cases of dehiscence of the facial canal. Dehiscence of the dural and sinus plates was observed in two cases each. Eight patients underwent mastoidectomy, and one underwent debridement with canalplasty.

Conclusion Review of the clinical and radiological findings is essential to reduce the rate of misdiagnosis.
\end{abstract}

\section{Introduction}

External auditory canal cholesteatoma (EACC) is a rare clinical entity. Its incidence is of 1 in every 1,000 new patients visiting the otology clinic. ${ }^{1}$ It was first described by Toynbee in $1850 .^{2}$ In 1980 , Piepergerdes et al. ${ }^{3}$ distinguished EACC from keratosis obturans. There is osteonec- rosis and formation of bony sequestrum in EACC. Bony erosion of the walls of the external auditory canal (EAC) and its spread to adjacent structures is frequently observed.

The clinical symptoms commonly observed are otorrhoea, otalgia, hearing loss, aural fullness, and itching. Some cases may be asymptomatic, and other cases may present with complications like facial palsy. The rarity of this condition received

July 11,2020

accepted

December 12, 2020

published online

August 19, 2021
DOI https://doi.org/ 10.1055/s-0041-1726047. ISSN 1809-9777.

\footnotetext{
(c) 2021. Fundação Otorrinolaringologia. All rights reserved. This is an open access article published by Thieme under the terms of the Creative Commons Attribution-NonDerivative-NonCommercial-License, permitting copying and reproduction so long as the original work is given appropriate credit. Contents may not be used for commercial purposes, or adapted, remixed, transformed or built upon. (https://creativecommons.org/ licenses/by-nc-nd/4.0/)

Thieme Revinter Publicações Ltda., Rua do Matoso 170, Rio de Janeiro, RJ, CEP 20270-135, Brazil
} 
and its nonspecific clinical findings often lead to misdiagnosis. The radiological investigation of choice is high-resolution computed tomography (HRCT) of the temporal bone. It helps to see the areas of bony erosion, the extent of the disease, and to plan the management of the patient. Many studies on EACC have focused on etiopathogenesis and epidemiology, and only a few studies have focused on clinical and radiological features. The objective of the present study is to describe the clinical presentation and radiological features of EACC.

\section{Material and Methods}

The present was a retrospective study conducted in the Department of Otorhinolaryngology of a tertiary referral center. Ethical approval was obtained from the Institutional Review Committee. The clinical records of all patients diagnosed with EACC from April 2017 to March 2020 were reviewed. Patients of all ages and genders visiting the ear, nose and throat (ENT) outpatient department with the diagnosis of EACC were included in the study. Patients with the diagnosis of cholesteatoma due to chronic otitis media, keratosis obturans, and necrotizing otitis externa were excluded.

The diagnosis of EACC was clinical. A detailed history was taken, and an aural examination was performed under the microscope (otomicroscopy). The patients with keratin debris in the EAC underwent removal, and the patients with aural polyp underwent polypectomy during the otomicroscopy, with the local infiltration of $2 \%$ lignocaine with $1: 2,00,000$ of adrenaline. EACC was defined as disruption of the skin of the EAC with cholesteatoma with underlying focal bony destruction. The final diagnosis of EACC was confirmed during surgery.

Preoperative HRCT of the temporal bone, with scans in $0.6-\mathrm{mm}$ cuts, was performed in all cases. The axial and coronal views of the HRCT were studied, including bone window and soft-tissue window. The clinical presentation, the findings on the HRCT of the temporal bone, as well as the treatment provided were analyzed. The Microsoft Excel (Microsoft Corp., Redmond, WA, US) software was used for data recording and analysis.

\section{Results}

We found 9 patients, 7 males and 2 females, with an average age of 30 years (range: 14 to 38 years) who had undergone surgery for EACC from April 2017 to March 2020. The disease was in the left ear in six cases, and in the right ear in three cases. There was no bilateral disease in the present study. The predisposing factors identified were smoking in two patients, and ear picking in four patients. Three patients didn't have any predisposing factors for EACC.

At our center, we see around 6,000 new otological cases each year, and the incidence of EACC is of 0.5 per 1,000 new otological patients.

Chronic otorrhoea was the most common symptom of all, with six out of the nine patients presenting with this symptom. It was followed by otalgia in three patients,

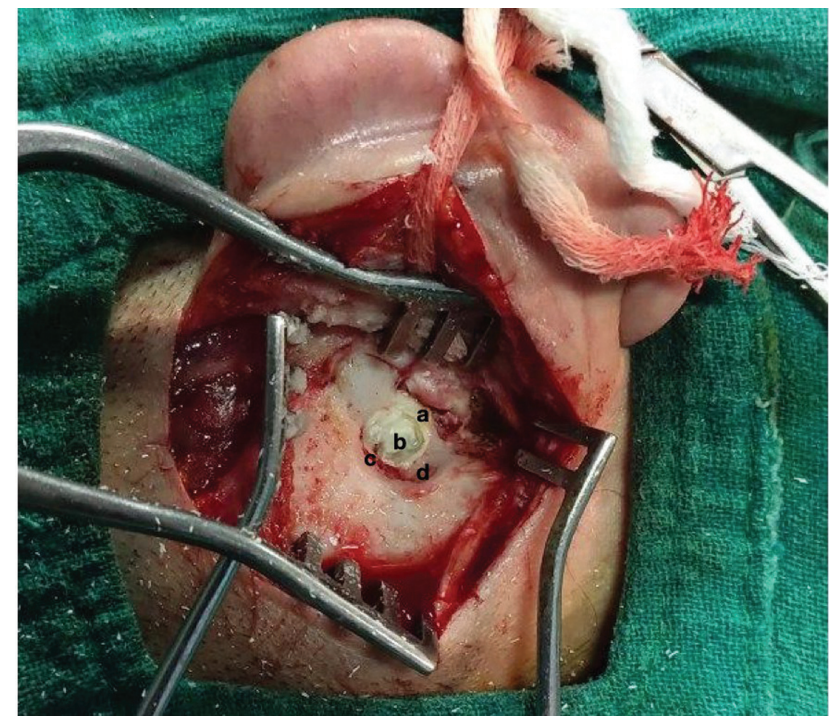

Fig. 1 External auditory canal cholesteatoma after elevation of the tympanomeatal flap via the postaural approach (a, anterior canal wall; b, external auditory canal cholesteatoma; $c$, destruction of the posterior canal wall; $\mathbf{d}$, destruction of the inferior canal wall).

reduced hearing in three patients, and facial palsy in one patient. Some patients had multiple complaints. On aural examination, six patients had destruction of the canal wall with cholesteatoma with intact tympanic membrane, two patients had an aural polyp, and one patient had sagging of the posterior canal wall, leading to a narrow ear canal. One of the patients with an aural polyp had grade-II facial nerve palsy. - Fig. 1 shows the cholesteatoma in the EAC after elevation of the tympanomeatal flap via the postaural approach.

On the HRCT of the temporal bone, there was soft-tissue density in the EAC with destruction of the canal wall in all nine cases (-Figs. 2 and 3). Five patients had erosion of the posterior canal wall, four had erosion of the inferior canal wall, two had erosion of the superior canal wall, and three had circumferential erosion of all the canal walls. More than one wall of the EAC was eroded in most of the cases, most commonly the posterior and the inferior walls. Mastoid

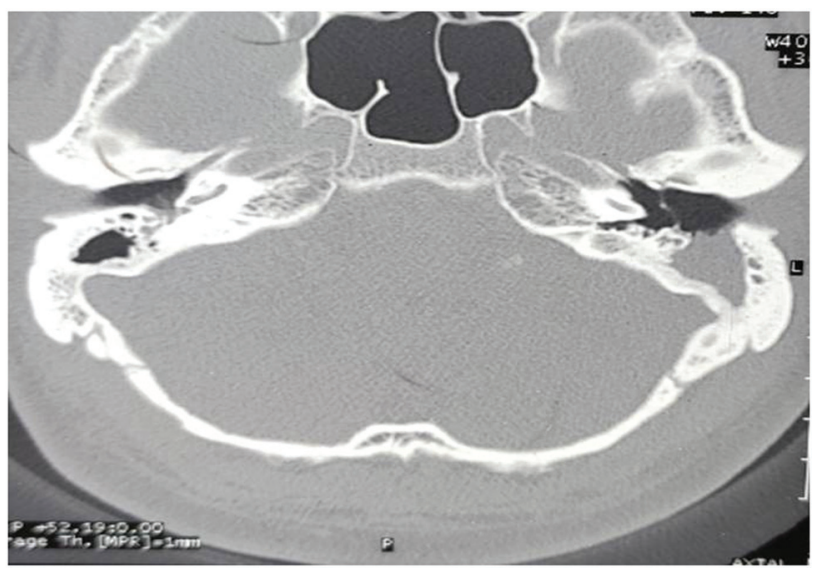

Fig. 2 High-resolution computed tomography of the temporal bone showing normal middle ear and bone destruction of the left posterior canal wall with extension of the soft tissue to the mastoid. 


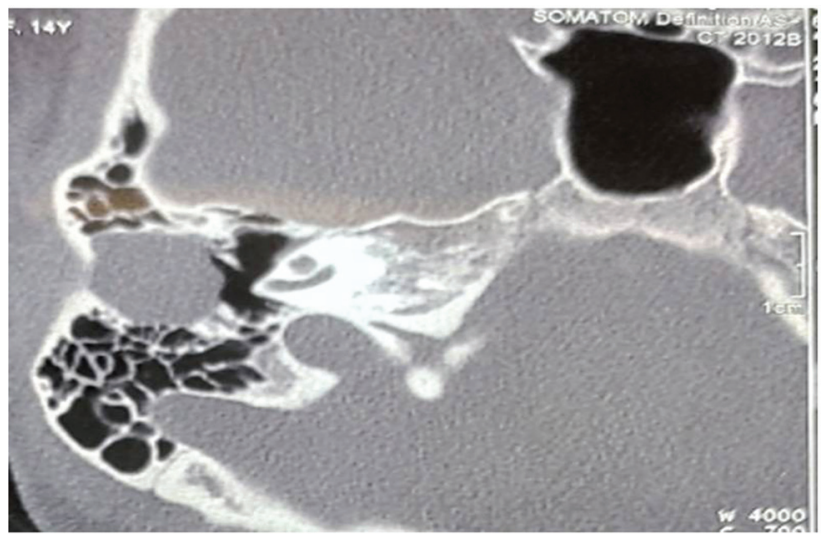

Fig. 3 High-resolution computed tomography of the temporal bone showing normal middle ear and soft-tissue density in the external auditory canal with circumferential bony destruction.

involvement was observed in eight patients. The sinus plate was dehiscent in two cases, as well as the dural plate. The facial nerve was dehiscent in three cases. Extension of the soft tissue to the middle ear was observed in one case.

All eight patients who had mastoid involvement underwent canal-wall-down mastoidectomy. One patient with the disease limited to the EAC underwent debridement of the cholesteatoma with canalplasty. The clinical and radiological characteristics of the patients are shown in -Table 1.

\section{Discussion}

Cholesteatoma is formed by stratified squamous epithelium which accumulates desquamated keratin debris and has the property of bone erosion. ${ }^{4}$ It is most commonly found in the middle-ear cavity and the mastoid; however, though rare, it can occur in the EAC. The annual incidence of EACC in the general population is of 0.15 cases per 100,000 individuals, as compared with 9.2 cases per 100,000 individuals per year for middle-ear cholesteatoma. ${ }^{4}$ Anthony and Anthony ${ }^{1}$ found an incidence of EACC of 1 per 1,000 new patients visiting in otology clinic. In the present study, the incidence of EACC was of 0.5 per 1,000 new otology patients.

In a study by Holt, ${ }^{5}$ the mean age of the patients with EACC was of 62 years. Piepergerdes et al. ${ }^{3}$ showed that EACC is a disease found in the elderly population. The mean age of the patients in the present study was 30 years, ranging from 14 to 38 years. This contradicts earlier studies, for EACC can also be found in younger patients.

$\operatorname{Tos}^{6}$ has classified EACC as primary, secondary, and cholesteatoma associated with congenital atresia of the external ear. In primary EACC, there is no obvious etiology. Secondary EACC may be due to previous trauma, surgery, radiation exposure, or chronic inflammation of the EAC. The most common forms of trauma are due to the use of Q-tips and poorly-fitted hearing aids. ${ }^{7}$

All of the nine cases in the present study, were of primary EACC. The exact pathogenesis behind the development of primary EACC is still unknown. Many studies ${ }^{8-11}$ state that primary EACC results from a reduced migratory capacity of the canal epithelium, which leads to "keratinization in situ."
However, Bonding and Ravn, ${ }^{12}$ in their study published in 2008 , showed no difference in the rate of epithelial migration between normal ears and those affected by EACC. Primary EACC has been epidemiologically linked with microtraumas and smoking, leading to microangiopathy in the ear canal, which causes keratin deposition due to poor blood supply. ${ }^{10,13}$ In the present study, the predisposing conditions identified were smoking and the habit of picking the ear. It has also been postulated that a piece of exposed bone in the auditory canal due to trauma becomes infected and sequestered, the epithelium migrates into this bony abnormality, and the cholesteatoma is formed. ${ }^{14}$ One study ${ }^{15}$ has linked primary EACC to anomalies of the branchial arch. Recently, immunohistochemical investigations ${ }^{16-18}$ found that the vascular endothelial growth factor and the hepatocyte growth factor were elevated in EACC specimens.

The clinical symptoms commonly observed are otorrhoea, otalgia, hearing loss, aural fullness, and itching. Some cases may be asymptomatic. In a meta-analysis, Dubach et $\mathrm{al}^{13}$ found the most common presenting symptoms of primary EACC to be unilateral otorrhoea and otalgia. In the present study, the most common symptom was otorrhoea (present in six patients). Otalgia and hearing loss were the other symptoms. One patient presented with chronic otorrhoea, aural polyp and grade-II facial palsy for two weeks. This patient had an EACC that extended to mastoid, eroding the vertical part of the facial canal, and the sinus and the plates. It is very rare to see a case of EACC leading to complications such as facial palsy. ${ }^{19}$ One rare case of EACC extending to the jugular foramen has been reported by Hartley et al. ${ }^{20}$ in 1995.

An aural examination may show focal areas of bony erosion in the EAC, with keratin debris, wax, or granulation with underlying cholesteatoma, aural polyp, stenosis, and sometimes widened canal due to bony erosion. The most common finding in the present study was erosion of the bony canal wall with keratin debris and intact tympanic membrane. The posterior and inferior canal walls were commonly eroded, as shown in the other studies. ${ }^{5,8,10}$ The tympanic membrane was intact in most of the cases in the present study, which is in line with the description made by Piepergerdes et al. ${ }^{3}$ for EACC. ${ }^{3}$ In the present study, there was one case of sagging of the posterior canal wall due to cholesteatoma, which lead to the destruction of that wall. Holt ${ }^{5}$ described dried up wax overlaying the cholesteatoma as a common finding in EACC. According to his study, the aging cerumen gland produces dried up wax that adheres to the skin of the ear canal, trapping desquamated epithelial cells. An aural examination was performed with otomicroscopy in the present study. However, the use of the otoendoscope for the diagnosis and treatment of EACC may have added benefits, due to its wide angle of view and better visualization. ${ }^{21,22}$

The variability in clinical spectrum of EACC often leads to misdiagnosis. A radiological investigation serves as an adjunct to diagnose this rare condition. However, there are only a few articles available which focus on the radiological features of EACC. ${ }^{8,10}$ High-resolution computed tomography of temporal bone helps in the diagnosis of EACC. It also helps to know the extent of the disease to plan the management of 


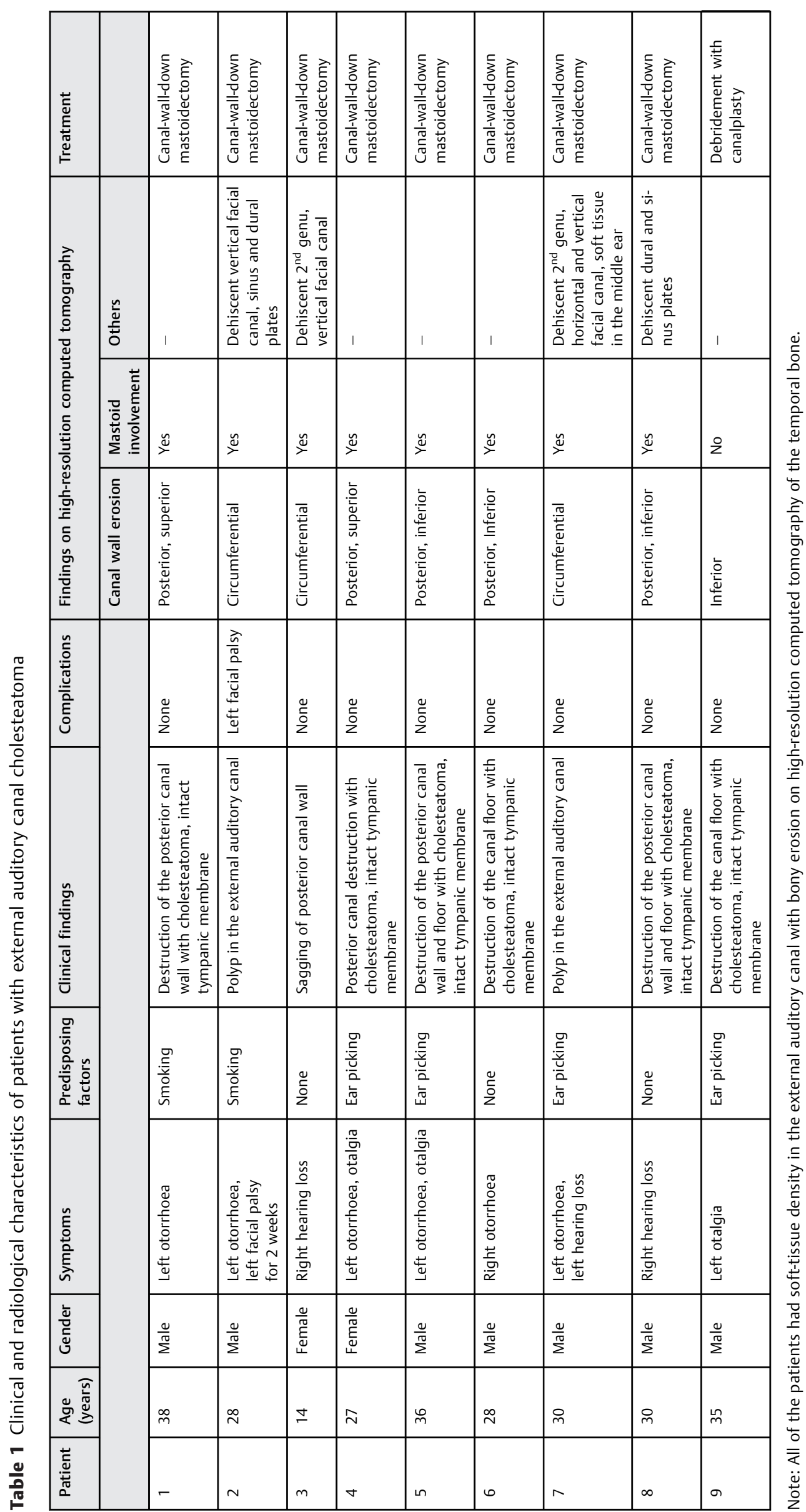


the patients. On the HRCT, EACC is observed as soft-tissue density in the EAC, with adjacent bony erosion and intramural bone fragments. ${ }^{10}$ The soft-tissue density may line the wall of the EAC, or it may occlude whole lumen of it, with bony erosion and variable extension to adjacent structures. The bone erosion may be smooth or irregular. ${ }^{10}$ The softtissue density and bony erosion were observed in all of the nine cases in the present study. In cases of primary EACC, the posterior and inferior canal walls are usually eroded, as obserfved in the present study. However, erosion of the anterior and superior canal walls, as well as circumferential erosion, may also be observed. Secondary EACC may show multifocal and random locations of bone erosion. ${ }^{23}$ On the HRCT, extension of the disease to the middle-ear cavity, mastoid, temporomandibular joint, dehiscence of the facial canal, labyrinth, semicircular canal, tegmen tympani and sinus plate should be observed, because these features may change the surgical management.

In 2010, Shin et al. ${ }^{24}$ staged EACC based on clinical and radiological findings: stage I is the disease limited to the EAC; stage II is the disease invading the tympanic membrane and the ear canal; stage III is the disease creating a defect of the ear canal and involving the cortex of the mastoid bone; and stage IV is the disease in areas beyond the temporal bone. This staging system is easy to follow, and it provides treatment plans according to each stage. In the present study, eight cases were in stage III, and one case was in stage I. All patients in stage III underwent canal-wall-down tympanomastoidectomy with meatoplasty. The patient in stage I underwent debridement of the cholesteatoma with canalplasty.

The differential diagnosis of EACC includes keratosis obturans, chronic otitis externa, necrotizing otitis externa, postinflammatory medial canal fibrosis, and neoplasms of the EAC. Clinical and radiological correlation helps to distinguish these conditions from EACC.

Keratosis obturans usually presents in younger patients with bilateral otalgia and conductive hearing loss. After removal of the keratin debris, gross widening/ballooning of the bony EAC will occur. ${ }^{3}$ However, in EACC, there will be focal bony erosion most of the times. Chronic otitis externa and postinflammatory medial canal fibrosis is differentiated from EACC on the basis of history and examination findings. There may be history of trauma, skin eczema, burns or previous surgery that predispose to chronic otitis externa. On aural examination, there may be granulation, edematous skin, fibrosis, or debris within the canal without bony erosions. ${ }^{4}$ A radiological investigation performed in cases of canal atresia postfibrosis will further help differentiate this condition from EACC. Necrotizing otitis externa (NOE) usually occurs in elderly patients with diabetes mellitus due to infection by Pseudomonas aeruginosa. Patients with NOE present with severe otalgia, otorrhoea and granulation tissue or edema in the EAC. Cranial nerve palsy is more frequently observed in NOE than in EACC. Apart from the HRCT of temporal bone, a technitium-99m (Tc-99m) radionuclide scan will help in the diagnosis by showing the bony involvement even before the bony erosion is visible. ${ }^{25}$ To distinguish
EACC from neoplasms of the EAC, tissue biopsy is of utmost importance, along with the radiological findings of the HRCT of the temporal bone and contrast-enhanced magnetic resonance imaging.

The limitations of the present study are its retrospective nature, with a small sample size and lack of data on the histopathological examination of the diseased epithelium. Further studies may be performed to compare the differences between the histopathological examination and the immunohistochemical markers of cholesteatomas of the EAC and those of the middle ear and the mastoid.

\section{Conclusion}

External auditory canal cholesteatoma is a rare condition. It can affect younger adults of any gender, as opposed to the previous belief that it only affected the elderly population. The common symptoms include otorrhoea, otalgia and hearing loss. Some patients may present with complications. The most commont finding on clinical examination is destruction of the posterior and inferior canal walls, with cholesteatoma or keratin debris and intact tympanic membrane. However, the patients may have variable clinical findings, which could lead to misdiagnosis. The most common finding on HRCT of the temporal bone is soft-tissue density in the EAC with bony erosion and variable extension to the adjacent structures. The findings of the HRCT of the temporal bone should be correlated the with clinical findings to formulate the correct diagnosis.

\section{Conflict of Interests}

The authors have no conflict of interests to declare.

\section{References}

1 Anthony PF, Anthony WP. Surgical treatment of external auditory canal cholesteatoma. Laryngoscope 1982;92(01):70-75

2 Toynbee J. Specimens of molluscum contagiosum developed in the external auditory meatus. Lond Med Gaz 1850;46(11): 261-264

3 Piepergerdes MC, Kramer BM, Behnke EE. Keratosis obturans and external auditory canal cholesteatoma. Laryngoscope 1980;90 (03):383-391

4 Gulya JA, Minor LB, Poe DS. Diseases of the Auricle, External Auditory Canal, and Tympanic Membrane. In: Glasscock-Shambaugh Surgery of the ear. 6th ed. Peoples Medical Publishing House-USA; 2010:379-396

5 Holt JJ. Ear canal cholesteatoma. Laryngoscope 1992;102(06): 608-613

6 Tos M. Cholesteatoma of the external acoustic canal. In: Manual of Middle Ear Surgery. Vol. 3. Surgery of the External Auditory Thieme, New York, USA1997:205-209

7 Dubach P, Häusler R. External auditory canal cholesteatoma: reassessment of and amendments to its categorization, pathogenesis, and treatment in 34 patients. Otol Neurotol 2008;29(07): 941-948

8 Owen HH, Rosborg J, Gaihede M. Cholesteatoma of the external ear canal: etiological factors, symptoms and clinical findings in a series of 48 cases. BMC Ear Nose Throat Disord 2006;6(01):16

9 Makino K, Amatsu M. Epithelial migration on the tympanic membrane and external canal. Arch Otorhinolaryngol 1986;243 (01):39-42 
10 Heilbrun ME, Salzman KL, Glastonbury CM, Harnsberger HR, Kennedy RJ, Shelton C. External auditory canal cholesteatoma: clinical and imaging spectrum. AJNR Am J Neuroradiol 2003;24(04):751-756

11 Naim R, Linthicum F Jr, Shen T, Bran G, Hormann K. Classification of the external auditory canal cholesteatoma. Laryngoscope 2005;115(03):455-460

12 Bonding P, Ravn T. Primary cholesteatoma of the external auditory canal: is the epithelial migration defective? Otol Neurotol 2008; 29(03):334-338

13 Dubach P, Mantokoudis G, Caversaccio M. Ear canal cholesteatoma: meta-analysis of clinical characteristics with update on classification, staging and treatment. Curr Opin Otolaryngol Head Neck Surg 2010;18(05):369-376

14 Watkinson JC, Clarke RW. Keratosis obturans, primary auditory canal cholesteatoma and benign necrotizing otitis externa. In: Scott-Brown's Otorhinolaryngology Head \& Neck Surgery. 8th ed. CRC Press; 941-8

15 Hickey SA, Scott GA, Traub P. Defects of the first branchial cleft. J Laryngol Otol 1994;108(03):240-243

16 Adamczyk M, Sudhoff H, Jahnke K. Immunohistochemical investigations on external auditory canal cholesteatomas. Otol Neurotol 2003;24(05):705-708

17 Naim R, Riedel F, Hormann K. Expression of vascular endothelial growth factor in external auditory canal cholesteatoma. Int J Mol Med 2003;11(05):555-558
18 Naim R, Shen T, Riedel F, Bran G, Sadick H, Hormann K. Regulation of apoptosis in external auditory canal cholesteatoma by hepatocyte growth factor/scatter factor. ORL J Otorhinolaryngol Relat Spec 2005;67(01):45-50

19 Belcadhi M, Chahed H, Mani R, Bouzouita K. Therapeutic approaches to complicated cholesteatoma of the external auditory canal: a case of associated facial paresis. Ear Nose Throat J 2010 ; 89(08):E1-E6

20 Hartley C, Birzgalis AR, Hartley RH, Lyons TJ, Farrington WT. External ear canal cholesteatoma. Case report. Ann Otol Rhinol Laryngol 1995;104(11):868-870

21 Abtahi SH, Abootalebian F, Rogha M, Berjis N. The value of otoendoscopy in the management of middle ear cholesteatoma. J Res Med Sci 2015;20(12):1182-1185

22 Tarabichi M. Endoscopic transcanal middle ear surgery. Indian J Otolaryngol Head Neck Surg 2010;62(01):6-24

23 Hn U, Prasad SC, Russo A, Grinblat G, Sanna M. Cholesteatoma of the external auditory canal: review of staging and surgical strategy. Otol Neurotol 2018;39(10):e1026-e1033

24 Shin S-H, Shim JH, Lee H-K. Classification of external auditory canal cholesteatoma by computed tomography. Clin Exp Otorhinolaryngol 2010;3(01):24-26

25 A Simon Carney. Malignant otitis externa. In: Gleeson M, editor. Scott-Brown's Otorhinolaryngology, Head and Neck Surgery. 7th ed. Vol 3. London: Edward Arnold; 2008:3336-41 